\title{
Analisa Pelatihan dan Pengembangan Sumber Daya Manusia pada PD. BPR Bank BAPAS 69 Kabupaten Magelang
}

\author{
Rendha Wahyu Pratiwi' ${ }^{1)}$, Budi Hartono ${ }^{2)}$ \\ ${ }^{1}$ Fakultas Ekonomi, Universitas Tidar \\ email: rendhapratiwi20@gmail.com \\ ${ }^{2}$ Fakultas Ekonomi, Universitas Tidar \\ email: hartono.budi@untidar.ac.id
}

\begin{abstract}
This study aims to explain the training analysis and development of existing PD. BPR BANK BAPAS 69 Magelang Regency. This study explains the analysis of needs, methods, types, objectives and benefits, as well as evaluating training and development. This study uses a qualitative approach, with data collection methods using observation, interviews, and documentation techniques. The results of this study indicate that the purpose of training and development is to improve the quality of human resources they have and is also useful for encouraging the progress of individuals and organizations. PD. BPR BANK BAPAS 69 uses organizational needs analysis, using two training and development methods, namely the classroom and simulation methods. The training and development carried out is formal or official because it has been planned by the organization. The evaluation is based on the value obtained from the trainer, then reviewed further and then used as material for consideration of determining career path or promotion.
\end{abstract}

Keywords: Training, Development, Human Resources.

\section{Abstrak}

Penelitian ini bertujuan untuk menjelaskan mengenai analisis pelatihan dan pengembangan yang ada PD. BPR BANK BAPAS 69 Kabupaten Magelang. Penelitian ini menjelaskan mengenai analisis kebutuhan, metode, jenis, tujuan dan manfaat, serta evaluasi mengenai pelatihan dan pengembangan. Penelitian ini menggunakan pendekatan kualitatif, dengan metode pengumpulan data menggunakan Teknik observasi, wawancara, dan dokumentasi. Hasil penelitian ini menunjukan bahwa tujuan dari pelatihan dan pengembangan adalah untuk meningkatkan kualitas SDM yang dimiliki dan juga bermanfaat untuk mendorong kemajuan individu dan organisasi. PD. BPR BANK BAPAS 69 menggunakan analisis kebutuhan organisasi, dengan memakai dua metode pelatihan dan pengembangan yaitu metode ruang kelas dan simulasi. Pelatihan dan pengembangan yang dilakukan bersifat formal atau resmi karena telah direncanakan oleh organisasinya. Evaluasi yang dilakukan berdasarkan pada nilai yang diperoleh dari trainer, kemudian dikaji lebih lanjut untuk kemudian digunakan sebagai bahan pertimbangan penentuan jenjang karir atau promosi.

Kata Kunci: Pelatihan; Pengembangan; Sumber Daya Manusia.

\section{A. PENDAHULUAN}

Bank merupakan suatu lembaga keuangan yang berfungsi untuk menghimpun dana dari masyarakat dan bisa disalurkan lagi ke masyarakat lainnya yang membutuhkan uang, sehingga bisa membuat taraf hidupnya meningkat. Penghimpunan dana itu 
dilakukan dengan berbagai cara seperti pembukaan rekening baru, deposito, giro maupun bentuk simpanan lainnya. Menurut UU No 10 Tahun 1998, bank memiliki tujuan yaitu menunjang pelaksanaan pembangunan nasional dalam rangka meningkatkan pemerataan, pertumbuhan ekonomi, dan stabilitas nasional ke arah peningkatan kesejahteraan rakyat. Suatu bank eksistensinya tergantung mutlak pada kepercayaan dari para nasabahnya yang mempercayakan dana simpanannya, untuk itu memerlukan dukungan dari Sumber Daya Manusia (SDM) yang dimilikinya.

Sumber Daya Manusia (SDM) sendiri merupakan aset utama dan paling berharga yang dimiliki oleh bank (Tilon 2013), sehingga harus memiliki kualitas yang tinggi untuk bisa menghasilkan kinerja yang baik. Untuk mempertahankan atau bahkan meningkatkan kualitas dari karyawan yang dimiliki, bank perlu mengadakan program pelatihan dan pengembangan, dimana program itu merupakan salah satu indikator yang berpengaruh terhadap Sumber Daya Manusia (SDM) karena merupakan cara untuk meningkatkan kemampuan, pengetahuan, keahlian dan keterampilan karyawan, terutama untuk menghadapi persaingan bisnis yang semakin ketat.

Mengingat di zaman modern sekarang ini, jika hanya mengandalakan ilmu formal saja tidak cukup untuk memenuhi tuntutan di dalam pekerjaan, dimana ilmu itu bersifat dinamis atau mudah berubah, selain itu persaingan antar bank juga semakin meningkat. Dengan adanya program pelatihan dan pengembangan para karyawan bisa mengupgrade ilmunya dan menambah kemampuan sesuai dengan keadaan sekarang.

Pelatihan dan pengembangan memiliki perbedaan. Pelatihan merupakan proses peningkatan kemampuan fisik dari karyawan sehingga dapat membantu tercapainya tujuan organisasi dimana pada dasarnya pelatihan ini cenderung lebih fokus pada jangka pendek (Rahman dan Titik 2015), sedangkan pengembangan merupakan usaha yang dilakukan untuk meningkatkan kemampuan karyawan sendiri guna menghadapi persaingan di masa yang akan datang.

PD.BPR BANK BAPAS 69 merupakan salah satu Bank Perkreditan Raktyat yang ada di Magelang. PD. BPR BANK BAPAS 69 terletak di Jalan Jend. Sarwo Edhie Wibowo, Sarangan, Banyurojo, Kecamatan Mertoyudan, Magelang, Jawa Tengah 56172. PD. BANK BAPAS 69 merupakan bank perkreditan rakyat nomer 1 se Indonesia, dan telah menjadi salah satu BUMD penyumbang PAD APBD terbesar di Kabupaten Magelang. Untuk itu diperlukan kegiatan pelatihan dan pengembangan guna 
mempertahankan predikat tersebut, karena membutuhkan kualitas SDM yang selalu baik dan meningkat untuk mendukung segala hal demi kemajuannya.

\section{B. TINJAUAN PUSTAKA}

\section{Pengertian Pelatihan dan Pengembangan SDM}

Kegiatan pelatihan dan pengembangan merupakan sebuah aktivitas yang tidak bisa dipisahkan dari kegiatan SDM. Pelatihan dan pengembangan ini, merupakan salah satu usaha yang dilakukan perusahaan guna meningkatkan kinerja SDM nya, serta untuk mengurangi kesenjangan antara kemampuan individu SDM dengan keinginan yang dikehendaki perusahaan.

Program pelatihan SDM sendiri didasari oleh faktor-faktor antara lain sebagai pengembangan Ketrampilan SDM, Untuk persiapan regenerasi SDM, serta guna mengembangkan kemampuan sesuai dengan kemajuan zaman dan teknologi (Iswara 2018). Dalam pasal 1 ayat (9) Undang-Undang Republik Indonesia No.13 tentang ketenagakerjaan, pelatihan adalah keseluruhan kegiatan untuk memberi, memperoleh, meningkatkan, serta mengembangkan kopetensi, produktivitas, disiplin, sikap dan etos kerja pada tingkat keterampilan dan keahlian tertentu sesuai dengan jenjang dan kualifikasi jabatan dan pekerjaan. Pelatihan merupakan sebuah proses dimana orangorang mencapai kemampuan tertentu untuk membantu tercapainya tujuan organisasi (Robert Mathis dan Jackson, 2002). Sedangkan pelatihan menurut Henry Simamora (2004) adalah proses pembelajaran yang melibatkan perolehan keahlian, konsep, peraturan, atau sikap untuk meningkatkan kinerja karyawan.

Dari beberapa pengertian diatas, pelatihan dapat disimpulkan bahwa merupakan sebuah proses untuk menambah pengetahuan, meningkatkan kopetensi, melatih ketrampilan serta kemampuan karyawan guna mewujudkan tujuan perusahaan.Pelatihan ini dimaksudkan untuk memperbaiki penguasaan berbagai keterampilan dan Teknik pelaksanaan kerja tertentu, terperinci, dan rutin.

Pengembangan SDM merupakan bagian terintegrasi dari Manajemen SDM dimana tujuannya adalah untuk meningkatkan kualitas individu. Pengembangan SDM adalah suatu usaha untuk meningkatkan kemampuan teknis, teoritis, konseptual, dan moral SDM (karyawan) sesuai dengan kebutuhan pekerjaan atau jabatan melalui pendidikan dan pelatihan. Menurut Lolowang, Adulfina, \& Lumintang (2016) pengembangan SDM 
merupakan upaya yang dilakukan untuk membentuk personal yang berkualitas serta memiliki keterampilan, kemampuan kerja dan loyalitas kerja terhadap perusahaan. Menurut Singodimejo (2000) pengembangan SDM merupakan proses persiapan individu guna memikul tanggung jawab yang berbeda atau lebih tinggi di organisasi, biasanya berkaitan dengan peningkatan kemampuan intelektual untuk menjalankan pekerjaan yang lebih baik. Dalam konteks SDM, pengembangan ini dipandang sebagai cara peningkatan SDM melalui pelatihan maupun pendidikan.

Manfaat dengan adanya suatu program pengembangan yaitu meningkatkan kepuasan karyawan, mengurangi pemborosan, mengutangi tingkat absen dan turnover, memperbaiki sistem kerja, menaikan tingkat pendapatan, mengurangi pengeluaran untuk lembur, mengurangi biaya pemeliharaan mesin, mengurangi keluhan dari para karyawan, mengurangi angka kecelakaan, memperbaiki komunikasi, meningkatkan pengetahuan, meningkatkan kerja sama yang baik, memperbaiki moral karyawan (Wijaya 2013).

\section{Tujuan dan Manfaat Pelatihan dan Pengembangan SDM}

Secara umum, tujuan pelatihan dan pengembangan yaitu untuk meningkatkan produktifitas baik dari sisi organisasi maupun individu karyawan tersebut. Pelatihan dan pengembangan ini dilakukan untuk menyediakan SDM (karyawan) yang siap pakai baik dari sisi kompetensi, manajerial, maupun prilaku. Pelatihan dan pengembangan ini tentunya juga memiliki tujuan untuk bisa menyiapkan kaderisasi atas jabatan yang akan dikembangkan oleh perusahaan di masa yang akan datang.

Menurut Shinta (2019) tujuan dari pengembangan SDM (karyawan) sendiri menyangkut beberapa hal, seperti meningkatkan produktivitas kerja, meningkatkan efisiensi tenaga, mengurangi kerusakan terhadap peralatan kerja, mengurangi kecelakaan, meningkatkan kualitas pelayanan, terciptanya moral yang lebih baik, meningkatkan karir karyawan, konseptual, meningkatkan jiwa kepemimpinan, meningkatkan insentif, menciptakan consumer satisfaction.

Tujuan dan manfaat dari pelatihan dan pengembangan menurut Mangkunegara (2008) antara lain adalah meningkatkan penghayatan jiwa maupun ideologi, meningkatkan produktivitas dan kualitas kerja, meningkatkan ketetapan perencanaan SDM, meningkatkan sikap moral dan keselamatan kerja, meningkatkan dan menambah rangsangan agar pegawai mampu berprestasi semaksimal mungkin, meningkatkan 
kesehatan dan keselamatan kerja, menghindari keusangan akibat perkembangan zaman dan teknologi, meningkatkan perkembangan individu SDM.

\section{Analisis Kebutuhan Pelatihan dan Pengembangan SDM}

Sebelum melakukan kegiatan pelatihan dan pengembangan, perusahaan harus mengerti untuk apa kegiatan pelatihan dan pengembangan dilakukan. Untuk itu diperlukan analisis terhadap kebutuhan pelatihan dan pengembangan. Analisis pelatihan dan pengembangan itu lebih dikenal dengan Training Need Analysis. Menurut Mathis dan Jackson (2010) terdapat tiga pertimbangan untuk perusahaan melakukan analisis kebutuhan pelatihan dan pengembangan yaitu :

1. Kebutuhan Organisasi

2. Kebutuhan Pekerjaan yang akan dilakukan

3. Kebutuhan Individu Karyawan

\section{Jenis Pelatihan dan Pengembangan SDM}

Menurut Hasibuan (2016), pelatihan dan pengembangan ini dibedakan menjadi 2 jenis yaitu :

1. Pelatihan dan pengembangan secara formal, dilakukan secara resmi oleh perusahaan untuk para karyawannya, secara terstruktur, terjadwal, dan terperinci dengan mengacu pada silabus yang ada.

2. Pelatihan dan pengembangan secara informal, dilakukan karyawan atas keinginan dan usahanya sendiri untuk mengembangkan dirinya dengan cara membaca literatur atau buku-buku yang berhubungan dengan pekerjaannya. Bisa dikatakan juga bahwa pelatihan informal diadakan untuk melengkapi pelatihan formal.

\section{Metode Pelatihan dan Pengembangan SDM}

Terdapat banyak sekali metode pelatihan SDM. Menurut Shinta (2019) metode pelatihan yang paling terkenal dan yang paling banyak digunakan ada 6 macam, antara lain adalah :

\section{Metode On the job training}

Merupakan metode yang menempatkan peserta secara langsung di tempat pelatihan dan pengembangan guna bisa langsung belajar dan meniru suatu pekerjaan dimana juga masih dibawah bimbingan pengawas. 
2. Metode Vestibule atau balai

Merupakan metode yang dilakukan di dalam ruangan, dimana metode ini cocok untuk banyak peserta (karyawan baru) yang dilatih dengan jenis pekerjaan yang sama dan dalam waktu yang sama.

3. Metode Demonstrasi dan contoh

Merupakan metode pelatihan yang dilakukan dengan cara demonstrasi menunjukan dan merencanakan bagaimana suatu pekerjaan atau bagaimana sesuatu itu dilakukan.

4. Metode Simulasi

Metode pelatihan ini merupakan suatu situasi atau peristiwa untuk menciptakan bentuk realitas atau imitasi dari realitas yang ada. Pelatihan ini dilakukan untuk memberi contoh dengan menciptakan situasi semirip mungkin dengan situasi sebenarnya.

5. Metode Apprenticeship

Metode ini merupakan suatu cara untuk mengembangkan keterampilan (skill) pengrajin atau pertukangan, sehingga peserta yang bersangkutan bisa mempelajari segala aspek mengenai pekerjaannya.

6. Metode Ruang kelas

Metode ini merupakan metode yang dilakukan di dalam kelas walaupun dapat dilakukan diarea pekerjaan yang meliputi pengajaran, rapat, intruksi yang terprogram, studi kasus, role playing, diskusi, dan seminar.

\section{Peserta Pelatihan dan Pengembangan SDM}

Peserta pelatihan dan pengembangan pastinya seluruh karyawan yang ada di perusahaan tersebut. Yang membedakan kemungkinan hanya materi yang disampaikan, sebab karyawan baru dan karyawan lama pastinya akan menerima tambahan ilmu yang berbeda.

\section{Evaluasi Pelatihan dan Pengembangan SDM}

Untuk mengetahui hasil setelah dilakukannya kegiatan pelatihan dan pengembangan perlu diadakan pengevaluasian. Menurut Shinta (2019), terdapat empat kriteria dasar yang dapat dievaluasi, yaitu : 


\section{Reaksi}

Fokus pada pemahaman dan reaksi peserta terhadap tujuan kegiatan pelatihan dan pengembangan serta proses pelaksanaan secara keseluruhan.

2. Penugasan

Menilai sejauh mana para peserta benar-benar telah menguasai konsep, informasi, serta prinsip-prinsip tentang keterampilan dan pengetahuan yang telah diberikan.

3. Sikap

Perubahan sikap dan perilaku para peserta dalam melakukan pekerjaan dan tugasnya sebagai hasil dari pelaksanaan kegiatan.

4. Hasil

Hasil akhir dalam hal ini dapat berupa indicator-indikator kinerja yang nyata seperti kenaikan produktifitas, peningkatan laba, penurunan biaya, penurunan tingkat kesalahan, peningkatan kualitas, penurunann keluhan pelanggan.

\section{METODE PENELITIAN}

Penelitian ini digunakan dengan penelitian jenis kualitatif deskriptif, dimana data yang dihasilkan bukan berupa angka-angka melainkan berupa kata-kata ataupun gambar. Penelitian kualitatif adalah penelitian dengan pengumpulan data pada suatu tempat atau lapangan dengan maksud untuk menafsirkan suatu fenomena yang terjadi dengan menggunakan berbagai metode yang ada.

Menurut Erickson (1968) penelitian kualitatif merupakan penelitian yang berusaha untuk menemukan serta menggambarkan dengan cara naratif terhadap kegiatan yang dilakukan dan dampak dari kegiatan itu terhadap kehidupan mereka. Sehinggapenelitian kualitatif deskriptif yaitu penelitian dengan mendeskripsikan dan menggambarkan fenomena-fenomena yang terjadi di suatu tempat. Penelitian ini dilakukan untuk mengetahui bagaimana cara untuk melatih dan mengembangkan Sumber Daya Manusia di PD. BPR BANK BAPAS 69 KABUPATEN MAGELANG.

Penelitian ini dilakukan di PD. BPR BANK BAPAS 69 Kantor Cabang Selatan dimana dilakukan selama 1 bulan mulai dari 13 Januari 2020 sampai dengan 13 Februari 2020. Dimana terletak di Jl. Jend. Sudirman no.76, Karanggading, Magelang Selatan dengan menggunakan 2 sumber data yaitu sumber data primer dan sekunder. Data primer 
diambil langsung pada Kantor Pusat PD. BPR BANK BAPAS 69 Kabupaten Magelang, sedangkan data sekunder diambil melalui majalah dan internet PD.BPR BANK BAPAS 69 itu sendiri. Dalam pengumpulan data penelitian ini dimana peneliti langsung terjun ke lapangan, sehingga digunakan 3 teknik yaitu observasi, wawancara, dan dokumentasi.

Penelitian ini menggunakan uji keabsahan data trianggulasi dengan menggunakan 3 analisis data yaitu reduksi data, penyajian data, penarikan kesimpulan dan verifikasi. Digunakannya trianggulasi karena untuk menggali informasi sedalam mungkin sehingga bisa menghasilkan informasi yang akurat dari para informan, gambar maupun dokumentasi itu sendiri. Trianggulasi merupakan Teknik pemeriksaan terhadap keabsahan data dengan membandingkan teori yang ada dengan hasil wawancara yang telah diperoleh sehingga menghasilkan informasi yang valid.

\section{HASIL DAN PEMBAHASAN}

\section{Tujuan Pelatihan dan Pengembangan SDM}

Tujuan pelatihan dan pengembangan pastinya dilakukan untuk menunjang kinerja SDM nya. Di PD. BPR BANK BAPAS 69 KABUPATEN MAGELANG kegiatan pelatihan dan pengembangan ini lebih dikenal dengan kegiatan Pendidikan dan pelatihan. Kegiatan Pendidikan pelatihan di PD. BPR BANK BAPAS 69 sendiri telah diatur setiap tahunnya karena kegiatan itu telah dianggarkan biayanya dimana itu sesuai dengan isi surat POJK No.47/PJOK.03/2017 Tahun 2017 untuk pengembangan mutu SDM.

Pendidikan dan pelatihan merupakan sebuah pintu pembuka untuk memasuki gerbang kemajuan kualitas SDM disebuah BPR. Dalam hal itu, PD. BPR BANK BAPAS 69 membentuk Bapas Training Center untuk menunjang SDM agar lebih kratif dan inovatif. SDM pada BPR merupakan subyek penting dalam bisnis apapun, untuk itu SDM perlu senantiasa melakukan up grading terus menerus.

Selain itu, pendidikan dan pelatihan pada PD. BPR BANK BAPAS 69 dilakukan guna mempersiapkan kaderisasi pemegang tonggak kepemimpinan dimasa yang akan datang, dan juga untuk mempersiapkan SDM yang ada di lingkungan BANK BAPAS 69 dalam menghadapi era digitalisasi.

\section{Analisis Kebutuhan Pelatihan dan Pengembangan SDM}

Dari teori yang telah disampaikan Mathis dan Jackson (2010), analisis kebutuhan pelatihan dan pengembangan yang dilakukan oleh PD. BPR BANK BAPAS 69 adalah 
menggunakan analisis kebutuhan organisasi. Dilakukan dengan melakukan analisis terhadap kebutuhan organisasi selama 1 tahun ke depan. Misalnya mempersiapkan pengganti pejabat yang akan purna tugas, materi atau sertifikasi yang yang harus dipenuhi, dan kebutuhan individu untuk meningkatkan kinerja sumber daya manusia.

\section{Jenis Pelatihan dan Pengembangan SDM}

Sesuai dengan teori yang dikemukakan oleh Hasibuan (2016), jenis pelatihan dan pengembangan yang dilakukan oleh PD. BPR BANK BAPAS 69 hanya pelatihan formal saja.

\section{Metode Pelatihan dan Pengembangan SDM}

Berdasarkan hasil wawancara yang dilakukan oleh peneliti, dimana sesuai dengan teori yang telah disampaikan Shinta (2019) PD. BPR BANK BAPAS 69 menggunakan 2 metode pelatihan dan pengembangan yaitu metode ruang kelas dan metode simulasi. Metode ruang kelas dilakukan dengan cara presentasi dari para trainer untuk menyampaikan materi-materi yang teoritis. Sedangkan metode simulasi dilakukan dengan menyediakan media yang sama dengan pekerjaan sesungguhnya, kemudian dilakukan juga dengan forum diskusi untuk mencari solusi dari kendala-kendala yang ada.

\section{Peserta Pelatihan dan Pengembangan SDM}

Peseta pelatihan dan pengembangan di PD. BPR BANK BAPAS 69 ditujukan oleh seluruh karyawan, namun jika karywan itu mendekati purna tugas tidak libatkan untuk mengikutinya. Pelatihan dan pengembangan tidak dilakukan dengan serentak, tetapi dibagi menjadi beberapa kelompok tertentu. Dari kegiatan pelatihan dan pengembangan PD. BPR BANK BAPAS 69 memberikan fasilitas berupa sertifikat dan uang transport.

\section{Evaluasi Pelatihan dan Pengembangan SDM}

Evaluasi yang dilakukan oleh PD. BPR BANK BAPAS 69 berdasarkan pada nilai yang diperoleh dari trainer, kemudian dikaji lebih lanjut untuk kemudian digunakan sebagai bahan pertimbangan penentuan jenjang karir atau promosi.

\section{E. SIMPULAN}

Dari penelitian ini diperoleh suatu kesimpulan bahwa PD. BPR BAPAS 69 menganalisis kebutuhan pelatihan dan pengembangan dilihat berdasarkan kebutuhan organisasinya, dimana direncanakan untuk dilakukan selama 1 tahun kedapan dengan 
menggunakan jenis pelatihan formal atau resmi dengan memakai 2 metode yaitu metode ruang kelas dan metode simulasi. Dari penelitian yang telah dilakukan, saran yang bisa penulis sampaikan pada pihak PD. BPR BANK BAPAS 69 adalah Evaluasi kegiatan pelatihan dan pengembangan akan lebih baik jika dilakukan secara mendalam dengan memperhatikan 4 kriteria yaitu reaksi, penugasan, sikap, dan hasil.

\section{DAFTAR PUSTAKA}

Anggito,Albi dan Johan Setiawan.2018.Metodologi Penelitian Kualitatif.Sukabumi: CV Jejak.

Elfrianto.2016.Manajemen Pelatihan Sumber Daya Manusia Dalam Meningkatkan Mutu Lulusan.Jurnal EduTech.vol 2 no 2.20 April 2020.

Fitrah,Muh dan Luthfiyah.2017.Metodelogi Penelitian (Penelitian Kualitatif, Tindakan Kelas \& Studi Kasus.Sukabumi:CV Jejak.

Handoko,Hani.2014.Manajemen Personalia \& Sumber Daya Manusia. Yogyakarta:BPFE Yogyakarta.

Hasibuan,Melayu S.P.2016.Manajemen Sumber Daya Manusia.Jakarta:Salemba Empat. Iswara,Marvin Fernaldy.2018.Analisis Pelatihan dan Pengembangan Sumber Daya Manusia di PT Bank Centarl Asia Tbk Kantor Cabang Utama Solo Slamet

Riyadi.Agora.vol 6 no 01.25 Juni 2020.

Khurotin,Nurul dan Tri Wulida Afrianty.2018.Analisis Pelatihan dan Pengembangan Sumber Daya Manusia Di PT BEON INTERMEDIA CABANG MALANG.Jurnal Administrasi Bisnis.vol 64 no 1.24 April 2020.

Larasati,Sri.2018.Manajemen Sumber Daya Manusia.Yogyakarta:Deepublish Publisher. Mangkunegara,Anwar Prabu.2013.Manajemen Sumber Daya Manusia

Perusahaan.Bandung: PT. Remaja Rosdakarya.

Noor,Zulki Zulkifli.2012.Manajemen Sumber Daya Manusia.Yogyakarta:Deepublish.

Priyono dan Marnis.2008.Manajemen Sumber Daya Manusia.Surabaya:Zifatama

Publisher.

Purnaya,I Gusti Ketut.2016.Manajemen Sumber Daya Manusia.Yogyakarta:Penerbit Andi.

Rahman,Reza Winanda dan Titik Nurbiyanti.2015.Evaluasi Pelatihan dan Pengembangan Sumber Daya Manusia Pada Disiplin Kerja dan Kinerja Karyawan.JBTI.vol 6 no 2.25 Juni 2020.

Ratnawati,Shinta.2019.Manajemen Sumber Daya Manusia.Yogyakarta:Graha Cendikia. Rivai,Veithzal dan Ella Jauvani Sagala.2011.Manajemen Sumber Daya Manusia untuk

Perusahaan dari Teori ke Praktik.Jakarta: PT Raja Grafindo Sutrisno,Edy.2009.Manajemen Sumber Daya Manusia.Jakarta:Kencana. 
Tilon,Danny Albert.2013.Analisis Pelatihan dan Pengembangan Sumber Daya Manusia Pada Restoran A\&W Di City Of Tomorrow Surabaya.Agora.vol 1 no 3.25 Juni 2020.

Wijaya,Wendy.2013.Analisis Pelatihan dan Pengembangan Sumber Daya Manusia Pada Pabrik Kecap Wie Sin Di Lombok.Agora.vol 01 no 3.25 Juni 2020. 